\title{
The consequences of winter flock demography for genetic structure and inbreeding risk in vinous-throated parrotbills, Paradoxornis webbianus
}

\author{
J-W Lee, M Simeoni, T Burke and BJ Hatchwell \\ Department of Animal and Plant Sciences, University of Sheffield, Western Bank, Sheffield, UK
}

\begin{abstract}
The adaptive significance of flocking behaviour has been intensively studied, especially among birds, but the demography and genetic structure of winter flocks is poorly understood, despite their importance for many biological processes. For three successive winters, we studied the demography and genetic structure of winter flocks in a small passerine, the vinous-throated parrotbill Paradoxornis webbianus. Our objectives were to determine the match between observed demography and the genetic structure of winter flocks, and to investigate the consequences of kin structure for the risk of inbreeding during the breeding season. The size of five main study flocks ranged from 60 to 120 individuals. The sex ratio of each flock did not deviate from parity and survival rates of adults were moderately low (36 and 17\% in 2 years). Adults showed strong fidelity to a
\end{abstract}

winter flock not only within a season but also between years. As expected from observational data, we found significant genetic differentiation and isolation by distance among males and females in winter flocks at a fine spatial scale. Likewise, relatedness among individuals within a winter flock was significantly greater than between flocks. Despite these demographic and genetic circumstances, the inbreeding rate was relatively low $(4 \%)$. We conclude that fine-scale genetic structure occurs in the winter flocks of birds as a result of demographic processes without physical barriers. This genetic structure introduced a risk of inbreeding, but our evidence on whether individuals avoided incest was equivocal.

Heredity (2010) 104, 472-481; doi:10.1038/hdy.2009.135; published online 7 October 2009

Keywords: demography; inbreeding; genetic differentiation; microsatellite; vinous-throated parrotbill; winter flocks

\section{Introduction}

The frequency and distribution of alleles and genotypes within and among populations, that is the genetic structure of populations, has important consequences for many biological processes through its effects on demography and individual behaviour (Gabor et al., 1999; Gardner et al., 2001; Knutsen et al., 2003; Telfer et al., 2003; Postma and van Noordwijk, 2005; Cabe et al., 2006; Francisco et al., 2007; McEachern et al., 2007; Schweizer et al., 2007). Because of their high dispersal capacity by flight, it is generally assumed that gene flow within and among populations of birds may be less restricted than in other animal taxa such as mammals, amphibians or reptiles (Avise, 1996; van Treuren et al., 1999; Crochet, 2000). Nonetheless, some empirical studies have found significant genetic structure in avian populations at a large geographic scale of several hundreds kilometres range (Caizergues et al., 2003; Nicholls et al., 2006; Francisco et al., 2007) as well as at a fine spatial scale, measured at the level of territories or between social groups (Shorey et al., 2000; Double et al., 2005; Fowler, 2005; Temple et al., 2006; Woxvold et al., 2006).

Correspondence: Dr J-W Lee, Department of Animal and Plant Sciences, University of Sheffield, Western Bank, Sheffield S10 2TN, UK. E-mail: jinwonlee99@gmail.com

Received 24 April 2009; revised 11 August 2009; accepted 17

August 2009; published online 7 October 2009
Genetic differentiation may occur when there are physical barriers between populations or when the geographical distance between them exceeds the dispersal capacity of the species (Baker et al., 2001; Caizergues et al., 2003; Telfer et al., 2003; Garnier et al., 2004; Watts et al., 2004). However, it may also arise without physical barriers when behaviours such as territoriality, site fidelity or natal philopatry prevent the spatial mixing of genes (Sugg et al., 1996). In red grouse Lagopus lagopus scoticus, for example, Piertney et al., 1998 reported significant genetic divergence among 14 populations separated by 1 to $50 \mathrm{~km}$, and suggested that territoriality and natal philopatry were the main factors promoting such genetic differentiation. Similarly, genetic structure at a fine geographic scale is common in organisms with particular social systems (for example eusocial insects, cooperatively breeding birds and mammals) through the effects of dispersal patterns on kinship; such structure is often sex-specific when the sexes differ in their dispersal strategy (Sugg et al., 1996; Dobson, 1998; Storz, 1999; Ross, 2001). Genetic structure may, in turn, have important consequences for social and individual behaviours. For example, cooperation has evolved predominantly among relatives, through kin selection (Hamilton, 1964) and this is most likely to occur in kin-structured populations. On the other hand, interacting with kin may incur costs through kin competition that may nullify any kin-selected benefits (Taylor, 1992; West et al., 2002). Furthermore, if kin structure involves both sexes, there is a potential risk of 
incest and inbreeding depression (Keller and Waller, 2002), unless there are effective mechanisms of inbreeding avoidance (Pusey and Wolf, 1996). Therefore, we can expect complex interactions between demography, population structure and behaviour.

Flocking is a form of social behaviour observed across many animal taxa. Large flocks of birds beyond family association are commonly observed in the wild, especially in winter. Although the adaptive significance of flocking behaviour has been intensively studied (Krause and Ruxton, 2002), the demography and genetic structure of winter flocks is less well studied due to the difficulty of sampling and tracking a sufficient number of birds in wild flocks. Such winter flocks might be regarded as subpopulations (demes) if dispersal between them is limited and pairing occurs within a winter flock (Kim et al., 1992; Lemmon et al., 1997; Kim, 1998). Accordingly, winter flocks may have an important function in determining the social and genetic structures of populations (Sugg et al., 1996).

We studied the demography and genetic structure of winter flocks and the consequences for inbreeding risk during the breeding season in the vinous-throated parrotbill Paradoxornis webbianus, a small (ca. 10 g) passerine bird, which is a widely distributed, year-round resident in South Korea. Parrotbills are found in diverse habitats that include areas of dense bush and scrub. In winter (November-February), they form large, stable flocks of between 30 and 160 individuals in this study population (but see Severinghaus, 1987). Each flock has a finite wintering range that frequently overlaps the ranges of other flocks without antagonistic territorial behaviour (Severinghaus, 1987; Kim et al., 1992). Most adults stay in the same flock through a winter and pair formation occurs between birds in the same winter flock (Kim et al., 1992; Kim, 1998). Juveniles also show a degree of natal philopatry; about $40 \%$ of juveniles disperse to neighbouring flocks, whereas the rest remain in the same winter flock as their parents. Sibling coalitions that include both sexes are the rule in natal dispersal (Lee et al., in review). During the breeding season (AprilAugust), most individuals attempt to breed independently in monogamous pairs within their wintering ranges and there is male-oriented kin structure in nest dispersion (Kim, 1998; Lee et al., 2009), although this species is not a cooperative breeder.

On the basis of the nature of philopatry and flock fidelity in this species, we predict fine-scale genetic differentiation among winter flocks and a risk of inbreeding. The goals of this study were: (1) to determine the demography of winter flocks in terms of survival rate, adult movement and sex ratio; (2) to investigate, using microsatellites, whether the pattern of genetic structure of winter flocks is consistent with observed demographic features; and finally (3) to explore whether inbreeding occurs under these demographic and genetic circumstances.

\section{Materials and methods}

\section{Fieldwork}

The fieldwork was conducted at Buyoung-ri and Yangsu-ri, Yangseo-myeon, Yangpyeong-gun, Gyonggi-do, South Korea $\left(37^{\circ} 32^{\prime} \mathrm{N} 127^{\circ} 20^{\prime} \mathrm{E}\right)$ from December 2004 to January 2007, including two breeding seasons and three wintering seasons (2004-2005: the first winter; 2005-2006: the second winter; 2006-2007: the third winter). The study area (Figure 1) is about $5 \mathrm{~km}$ long and covers ca. 550 ha, including mountains surrounded by bush, reedbeds around a stream running through the study area, and scattered farmland and gardens. The study

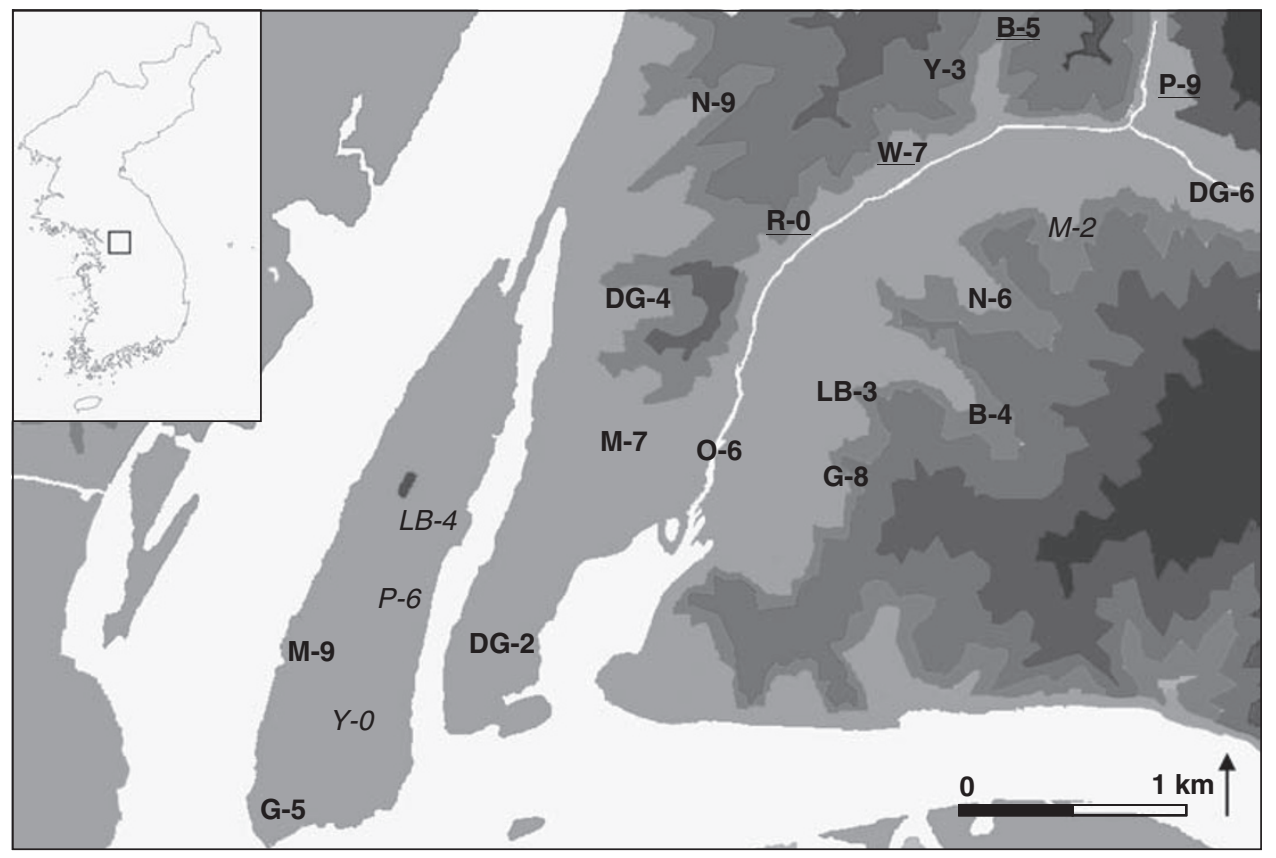

Figure 1 Topographic map of study area on Yangseo-myeon, Yangpyeong-gun, Korea, showing the locations of 21 winter flocks of vinousthroated parrotbills sampled for this study. Five main study flocks are underlined and flocks with italic names were excluded in the analysis. White area represents river or stream. Gradient of grey contour lines indicates height above sea level of 40 , 80 , 120 , 160 and $200 \mathrm{~m}$, respectively. 
area is divided into the main site (ca. 140 ha) occupied by five winter flocks (underlined names: R-0, W-7, Y-3, B-5, P-9; Figure 1) and the peripheral site (ca. 410 ha) that surrounds it and which contains about 16 winter flocks.

During each wintering season, we caught over $90 \%$ of the birds in the five main study flocks (size: 60-120 individuals per flock), using mist-nets. Each flock occupied the same area every winter and flock size was fairly constant among winters. In the second and third wintering seasons, we also caught the 16 peripheral flocks (size: $30-160$; capture rate: $>60 \%$ in most flocks). Each flock was identified based on the presence of regular individuals during repetitive captures and observation (Kim et al., 1992), and flock location was recorded using GPS, with which we determined the approximate central point of the wintering range of each flock; this point was used to estimate the distance between flocks. We also carried out additional catches of some winter flocks ( $n=7$ flocks) outside the peripheral study area in the second winter to locate any adults with long-distance movements from the main study flocks but none were found. Almost all birds caught in the study area $(n=2018)$ were ringed with metal rings and given unique combinations of colour rings. Blood samples $(10-30 \mu \mathrm{l})$ were also taken from the brachial wing vein and stored in absolute ethanol.

To investigate the level of inbreeding, we located nests in the main study area during the breeding seasons and identified the breeding pairs at each nest by direct observation and video-recording. Any unringed breeding birds were caught, ringed and bled during the incubation period.

\section{Demography}

Analyses of demographic processes such as adult movement, survival rate and sex ratio were performed using ringing data from the five main study flocks for three successive winters. Any individuals that transferred into the main study flocks from peripheral flocks, and vice versa, were also considered in the analysis of adult movements. The sex ratio (males/total) of each winter flock was determined based on molecular sexing (Griffiths et al., 1998). To examine the effect of sex and flock on adult survivorship, survival analysis was conducted in the $\mathrm{R}$ environment, version 2.7.0 ( $R$ Development Core Team, 2008). This analysis was conducted with the birds ringed in the first winter, in which the winter when each individual disappeared was recorded, and individuals which survived up to the third winter were recorded as being censored (see Crawley, 2007 for details). As noted earlier, long-distance movement by adults is extremely rare so we treated any disappeared birds as dead.

\section{Genotyping}

We used an ammonium acetate precipitation method for DNA extraction from blood (Nicholls et al., 2000). Fourteen microsatellite markers that had been originally isolated in other species were used for genotyping (LOX1, Calex-05, PmaD22, Aar4-Gga5, Pcau3, PAT MP2-43, Tgu07, TG11-011, Tc.11B4E-CEST(B), Tmm6, Escu6, ZL35, Tgu06, Pdo47; for details, see Lee et al., 2009 and references therein). The 14 microsatellite loci had a mean of 16 alleles per locus and an average heterozygosity of 0.72 across all samples from this study (see Supplementary information). Detailed PCR and genotyping procedure can be found in Lee et al. (2009).

\section{Genetic structure}

Genetic structure was analysed using 17 out of 21 winter flocks sampled in the second winter; 4 flocks (italic names, Figure 1) were excluded from the analysis because the capture rate was low. We adopted $F_{\mathrm{ST}}$ based approaches (Weir and Cockerham, 1984) to determine genetic structure of winter flocks. The level of genetic differentiation among winter flocks was measured by pairwise and overall $F_{\mathrm{ST}}$ (Weir and Cockerham, 1984), calculated in the program FSTAT version 2.3.9.2 (Goudet, $1995,2001)$ and the significance of the deviation of the estimates of $F_{\mathrm{ST}}$ from zero was assessed using the permutation procedure implemented in FSTAT, not assuming Hardy-Weinberg equilibrium. In a similar way, temporal genetic differentiation was analysed using the five main study flocks where sampling occurred consistently for 3 years. Using a permutation test in the program SPAGeDi version 1.2 (Hardy and Vekemans, 2002), we investigated isolation-by-distance by regressing pairwise $F_{\mathrm{ST}} /\left(1-F_{\mathrm{ST}}\right)$ against logarithms of geographic distance (ln-metres) among flocks (Rousset, 1997). Similarly, we conducted another random permutation procedure in SPAGeDi to test the correlates of relatedness (Queller and Goodnight, 1989) and spatial distance. We performed this spatial genetic autocorrelation analysis for each sex separately and between sexes; we represent birds from the same flock as being at a distance of $0 \mathrm{~m}$ and we let the program define 9 distance classes in such a way that the number of pairwise comparisons within each distance class is approximately constant. We computed genetic relatedness between individuals using the reference allele frequencies, which were made using all adult genotypes in SPAGeDi. We also tested sex-biased dispersal using the Biased Dispersal package in FSTAT, which generates $F_{\mathrm{ST}}$, mean $(\mathrm{m} A I c)$ and variance $(\mathrm{v} A I c)$ of assignment index for both sexes. Our sampling was carried out after the event of natal dispersal so it satisfies the prerequisite needed in this analysis (Goudet et al., 2002). In general, the dispersing sex tends to have lower $\mathrm{m} A I c$ and $F_{\mathrm{ST}}$, and larger vAIc than the philopatric sex (Goudet et al., 2002).

\section{Inbreeding}

We included breeding pairs only when we knew the preceding winter flock of both sexes. Genetic relatedness $(r)$ between members of a breeding pair as well as individuals within a winter flock was calculated using SPAGeDi based on the reference allele frequency described above. We considered a pairing to be inbred if the $r$ value between a male and a female was $>0.25$ because the expected $r$ value between half-siblings is 0.25 under Mendelian inheritance and our samples conformed well to this rule (Lee et al., 2009). To test whether the observed average $r$ values for pairs deviated significantly from randomly expected $r$ values, we carried out randomized permutation procedures in $\mathrm{R}$. We allowed the observed breeding females (2005: 25 females, 2006: 21 females) to mate randomly with males from the preceding winter flocks and calculated average $r$ values. Random pairings were generated only with 
males within the same winter flock as the observed females because most pairings observed were between members of the same winter flock. We repeated this 10000 times and the significance was determined based on whether the observed value of pairwise relatedness fell between the standard deviations of the expected mean at 0.05 level.

\section{Results}

Demography: survival rate and adult movement

In total, we caught 940 birds ( $>90 \%$ of all birds present) in the five main study flocks during three successive winters (Table 1). The average sex ratio of each flock for three winters did not deviate significantly from 1:1 (number of males/total \pm s.e.; R-0: $0.52 \pm 0.040$; W-7: $0.52 \pm 0.053 ; \quad$ Y-3: $\quad 0.48 \pm 0.010 ; \quad$ B-5: $0.52 \pm 0.026 ; \quad$ P-9: $0.53 \pm 0.055)$. There were no significant differences in recapture rates among flocks $\left(1 \mathrm{st} \rightarrow 2\right.$ nd winter: $\chi_{4}^{2}=2.5$, $P=0.64$; 2nd $\rightarrow$ 3rd winter: $\chi_{4}^{2}=2.3, P=0.67$; Table 1 ), but there was a significant difference in recapture rates in the two wintering seasons (36 vs $17 \%$; 2-sample test for equality of proportions: $\chi_{1}^{2}=33.1, P<0.001$; Table 1 ). From survival analysis of the birds caught in the first winter $(n=339)$, at least $60 \%$ of the birds disappeared every year and only about $10 \%$ of the birds ringed in the first winter were found in the third winter. Survival analysis also showed no significant difference among flocks $(P=0.91)$, or between adult males and females $(P=0.38)$.
Surviving adults showed strong winter flock fidelity; of 173 recaptured birds, just $7(4 \%)$ changed their winter flock between years ( 1 st $\rightarrow$ 2nd winter: $5 / 123$ birds, $4.1 \%$; 2 nd $\rightarrow$ 3rd winter: $2 / 50$ birds, $4 \%$ ), the remainder being recaptured in the same flock as in the preceding winter. There was a tendency for females to move more than males (6 females vs 1 male), including breeding dispersal by one pair and two examples of relatively long-distance movement; a female who moved to flock W-7 was originally caught in flock P-6 in the previous winter, a distance of about $3 \mathrm{~km}$, and another female who transferred to flock Y-3 was from flock LB-3 (see Figure 1). Overall, most of the adult males and females in our population stayed in the same winter flocks every winter.

\section{Genetic differentiation}

Overall $F_{\mathrm{ST}}$ values among 17 winter flocks was 0.01 , indicating small but significant genetic differentiation $(P<0.0001)$ at a fine spatial scale $(<5 \mathrm{~km}$, Figure 1$)$. Most pairwise $F_{\mathrm{ST}}$ values between flocks were also significantly different from zero (122 of 134, range: $0.0004-$ 0.025; Table 2). In addition, a significant isolation-bydistance effect across 17 winter flocks was detected over the small area of the study, although $r^{2}$ was small (Figure 2). The regression of pairwise $F_{\mathrm{ST}} /\left(1-F_{\mathrm{ST}}\right)$ against the logarithm of distance between flocks in metres deviated significantly from zero (slope $=0.0026$, permutation test $P=0.002$; Figure 2), indicating that most dispersal events, which may generate gene flow, were biased to the adjacent flocks.

Table 1 Summary of ringing recoveries of vinous-throated parrotbills in winter flocks over 3 successive years

\begin{tabular}{llccccc}
\hline Winter & \multicolumn{5}{c}{ Flock } \\
\cline { 2 - 6 } & \multicolumn{1}{c}{$R-0$} & $W-7$ & $Y-3$ & $B-5$ & P-9 & 31 \\
\hline $2004-2005$ & 71 & 70 & 83 & 54 & 339 \\
$2005-2006$ & $67(22,31 \%)$ & $79(29,41 \%)$ & $73(34,41 \%)$ & $47(14,26 \%)$ & $46(24,39 \%)$ & $312(123,36 \%)$ \\
$2006-2007$ & $80(8,12 \%)$ & $67(13,16 \%)$ & $60(15,21 \%)$ & $42(9,19 \%)$ & $40(5,11 \%)$ & $289(50,17 \%)$ \\
\hline
\end{tabular}

Data in the parentheses indicate the number of recaptured birds ringed in the previous winter and recapture rates.

Table 2 Estimates of pairwise $F_{\mathrm{ST}}$ among 17 winter flocks of vinous-throated parrotbills

\begin{tabular}{|c|c|c|c|c|c|c|c|c|c|c|c|c|c|c|c|c|c|}
\hline & $B-4$ & $B-5$ & $D G-2$ & $D G-4$ & $D G-6$ & $G-5$ & G-8 & $L B-3$ & $M-7$ & $M-9$ & $N-6$ & $N-9$ & $0-6$ & P-9 & $R-0$ & $W-7$ & $Y-3$ \\
\hline B-4 & & $* * *$ & NS & $*$ & $*$ & $* * *$ & $* * *$ & NS & $*$ & $* * *$ & $* *$ & $* *$ & $* * *$ & $* * *$ & $* *$ & $* * *$ & $* * *$ \\
\hline B-5 & 0.017 & & $* * *$ & $* * *$ & $* * *$ & $* * *$ & $* * *$ & $* * *$ & $* * *$ & $* * *$ & $* * *$ & $* * *$ & $* * *$ & $* * *$ & $* * *$ & $* * *$ & $* * *$ \\
\hline DG-2 & 0.006 & 0.019 & & NS & NS & $* * *$ & $* * *$ & NS & NS & $* * *$ & $* * *$ & $* * *$ & $* *$ & $* * *$ & NS & $*$ & $* * *$ \\
\hline DG-4 & 0.002 & 0.010 & 0.006 & & $* *$ & $* * *$ & $* * *$ & NS & $*$ & $* * *$ & $* *$ & $* *$ & NS & $*$ & NS & $*$ & $* *$ \\
\hline DG-6 & 0.001 & 0.018 & 0.006 & 0.005 & & $* * *$ & $* * *$ & $* *$ & $* *$ & $* * *$ & $* *$ & $* * *$ & $* * *$ & $*$ & NS & $* * *$ & $* * *$ \\
\hline G-5 & 0.009 & 0.022 & 0.013 & 0.009 & 0.013 & & $* * *$ & $* * *$ & $* * *$ & $* * *$ & $* * *$ & $* * *$ & $* * *$ & $* * *$ & $* * *$ & $* * *$ & $* * *$ \\
\hline G-8 & 0.009 & 0.019 & 0.018 & 0.008 & 0.015 & 0.015 & & $* * *$ & $* * *$ & $* * *$ & $* * *$ & $* * *$ & $* * *$ & $* * *$ & $* * *$ & $* * *$ & $* * *$ \\
\hline LB-3 & 0.001 & 0.013 & 0.009 & 0.001 & 0.008 & 0.007 & 0.009 & & $*$ & $* * *$ & $* *$ & $* * *$ & $* * *$ & $* * *$ & $*$ & $* * *$ & $* * *$ \\
\hline M-7 & 0.007 & 0.020 & 0.015 & 0.008 & 0.009 & 0.018 & 0.020 & 0.007 & & $* * *$ & $* * *$ & $* * *$ & $* * *$ & $* * *$ & * & $* * *$ & $* *$ \\
\hline M-9 & 0.008 & 0.025 & 0.013 & 0.012 & 0.012 & 0.008 & 0.015 & 0.010 & 0.017 & & $* * *$ & $* * *$ & $* * *$ & $* * *$ & $* * *$ & $* * *$ & $* * *$ \\
\hline N-6 & 0.005 & 0.015 & 0.012 & 0.005 & 0.007 & 0.016 & 0.009 & 0.006 & 0.012 & 0.013 & & $* * *$ & $* * *$ & $* * *$ & NS & $* * *$ & $* * *$ \\
\hline N-9 & 0.002 & 0.022 & 0.013 & 0.007 & 0.007 & 0.011 & 0.010 & 0.006 & 0.009 & 0.008 & 0.010 & & $* * *$ & $* * *$ & $* * *$ & $* * *$ & $* * *$ \\
\hline O-6 & 0.008 & 0.016 & 0.011 & 0.009 & 0.013 & 0.010 & 0.015 & 0.009 & 0.016 & 0.009 & 0.016 & 0.014 & & $* * *$ & $* * *$ & $* * *$ & $* * *$ \\
\hline P-9 & 0.008 & 0.019 & 0.014 & 0.008 & 0.007 & 0.015 & 0.021 & 0.012 & 0.018 & 0.017 & 0.021 & 0.017 & 0.013 & & $* * *$ & $* * *$ & $* *$ \\
\hline $\mathrm{R}-0$ & 0.003 & 0.011 & 0.007 & 0.0004 & 0.003 & 0.009 & 0.009 & 0.003 & 0.007 & 0.010 & 0.006 & 0.008 & 0.008 & 0.009 & & NS & NS \\
\hline W-7 & 0.005 & 0.015 & 0.007 & 0.003 & 0.007 & 0.012 & 0.012 & 0.006 & 0.009 & 0.012 & 0.011 & 0.011 & 0.008 & 0.011 & 0.001 & & $* * *$ \\
\hline$Y-3$ & 0.006 & 0.011 & 0.013 & 0.007 & 0.011 & 0.010 & 0.010 & 0.006 & 0.013 & 0.014 & 0.012 & 0.015 & 0.006 & 0.009 & 0.007 & 0.011 & \\
\hline
\end{tabular}

$F_{\mathrm{ST}}$ was estimated according to Weir and Cockerham (1984).

${ }^{*} P<0.05 ;{ }^{* *} P<0.01 ;{ }^{* *} P<0.001 ;$ NS, non-significant. 
476

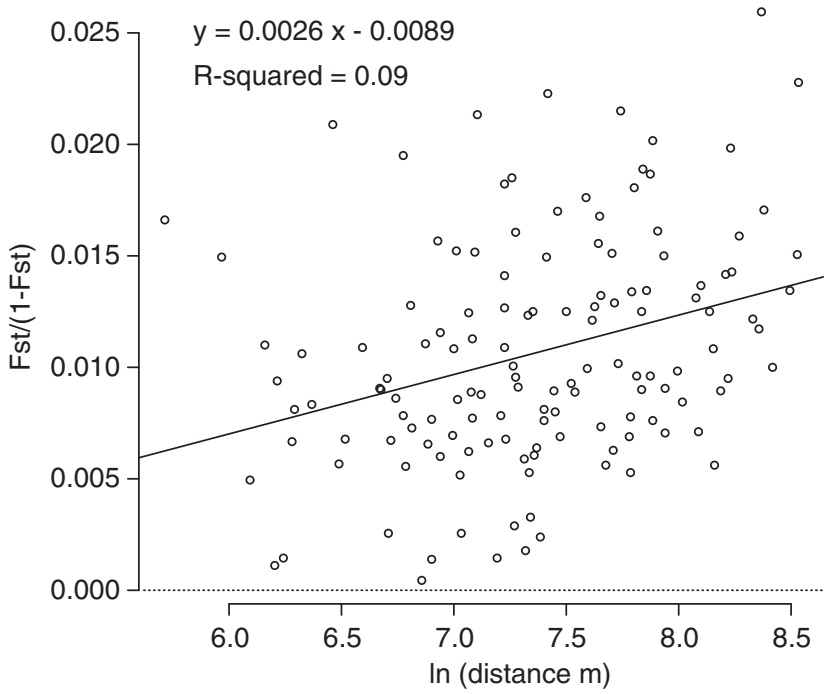

Figure 2 Genetic differentiation among winter flocks of vinousthroated parrotbills. Pairwise genetic differentiation between winter flocks are plotted against logarithm of distance (in metres) following Rousset (1997). $F_{\mathrm{ST}}$ was estimated according to Weir and Cockerham (1984).

Table 3 Estimates of temporal genetic differentiation $\left(F_{\mathrm{ST}}\right)$ in the five main study flocks of vinous-throated parrotbills

\begin{tabular}{lccc}
\hline Flock & 1st vs 2nd winter & 2nd vs 3rd winter & 1st vs 3rd winter \\
\hline R-0 & -0.0001 & 0.0006 & $0.0079^{* *}$ \\
W-7 & -0.0017 & -0.0007 & $0.0038^{*}$ \\
Y-3 & 0.0028 & $0.0019^{*}$ & $0.0027^{* *}$ \\
B-5 & $0.0041^{*}$ & $0.0047^{*}$ & $0.0062^{* *}$ \\
P-9 & -0.0022 & $0.0115^{* *}$ & $0.0094^{* *}$ \\
\hline
\end{tabular}

$F_{\mathrm{ST}}$ was estimated according to Weir and Cockerham (1984).

${ }^{*} P<0.05 ;{ }^{*} P<0.01$.

Temporal genetic differentiation within a flock was smaller than the spatial genetic differentiation between flocks (Table 3). For the five main study flocks during three successive winters, we found no significant difference between the first and second winter, except for flock B-5 (Table 3), and in two flocks (R-0, W-7), F $F_{\text {ST }}$ values between the second and third winters were still not significantly different from zero, despite a low recapture rate (see Table 1). Comparisons within flocks of first and third winter generated significant $F_{\mathrm{ST}}$ values (mean $=0.006 \pm 0.0012$ s.e.; Table 3 ), but the values were still smaller than those from comparisons among flocks (mean $=0.01 \pm 0.001$ s.e.; Table 2).

Consistent with genetic differentiation and the isolation-by-distance effect, there was significant relatedness within a flock. Spatial autocorrelation analysis revealed that both males $(P<0.0001$; Figure $3 a)$ and females $(P<0.0001$; Figure $3 \mathrm{~b})$ within the same flock were more closely related than expected by chance. Furthermore, the observed mean relatedness between males and females within a flock also deviated significantly from 95\% CI of mean relatedness expected from randomized permutation $(P=0.009$; Figure $3 \mathrm{c})$, indicating that males and females within a winter flock are more closely related than those in different flocks. This pattern might stem from the dispersal of mixed-sex sibling coalitions
(Lee et al., in review) and/or from natal philopatry of both sexes. Both $\mathrm{m} A I c$ and overall $F_{\mathrm{ST}}$ values from the analysis in FSTAT indicated that female-bias occurred in natal dispersal (Table 4; the more dispersive sex has a lower $\mathrm{mAIc}$ and $F_{\mathrm{ST}}$, Goudet et al., 2002). However, this result was marginal, despite large sample sizes (Table 4), indicating that the sex difference are equivocal and females as well as males are often philopatric.

\section{Inbreeding}

Close inbreeding did occur in our study population: $2 / 46$ (4\%) pairs were composed of a male and female with a pairwise relatedness estimate of $r>0.25$ (2005: $1 / 25$ pairs, 2006: 1/21 pairs). However, the genetic structure of winter flocks, described above, meant that most of the breeding females we studied $(42 / 46)$ had at least one related male $(r>0.25)$ in the preceding winter flock where mate choice occurred, and many had several relatives as potential partners (mean number of related males $=3.6 \pm 2.45$ s.e., range: $1-11$ ).

The observed rate of inbreeding may be lower than anticipated if pairing was random with respect to kinship, so can we conclude that the relatively low inbreeding rate was a result of active inbreeding avoidance behaviour? Average relatedness $(r)$ between breeding pairs $(n=46)$ was $0.01 \pm 0.151$ s.e. (2005 breeding pair $r=-0.02 \pm 0.157$ s.e., range: $-0.34-0.25$; 2006 breeding pair $r=0.05 \pm 0.136$ s.e., range: $-0.22-0.45$ ), which was not significantly lower than the average relatedness between breeding females and all prospective males in each flock in each year (Wilcoxon rank sum tests: $2005 r=0.04, P=0.1 ; 2006 r=0.04, P=0.6$ ). Furthermore, randomized permutation tests (10000 times) gave equivocal results regarding inbreeding avoidance. Observed average relatedness of breeding pairs was significantly lower than expected in 2005 $(P=0.04$; Figure 4), but not in $2006(P=0.9$; Figure 4$)$. Combining data across years, the relatedness of pairs did not differ significantly from random expectation $(P=0.16$; Figure 4$)$.

\section{Discussion}

\section{Demography}

Dispersal is a critical process in ecological and evolutionary biology (Hamilton and May, 1977; Arcese, 1989; Johnson and Gaines, 1990). Adult vinous-throated parrotbills exhibit strong winter flock fidelity within and between years. Juveniles including both sexes also show strong natal philopatry (Lee et al., in review); just $40 \%$ of juveniles moved away from their parents' flock to mostly neighbouring flocks in their first year, and for those juveniles that did disperse, sibling coalitions with both sexes were the norm (Lee et al., in review). These three demographic processes of natal philopatry, dispersal in kin groups and fidelity to winter flocks by adult vinous-throated parrotbills would collectively be expected to generate flocks comprised of a number of kin groups and hence populations exhibiting significant genetic structure, as we have found in this study.

We have reported elsewhere (Lee et al., 2009) that kin association during breeding may have fitness benefits in terms of productivity, but there may also be costs of competing with kin (Taylor, 1992), so the dispersal 

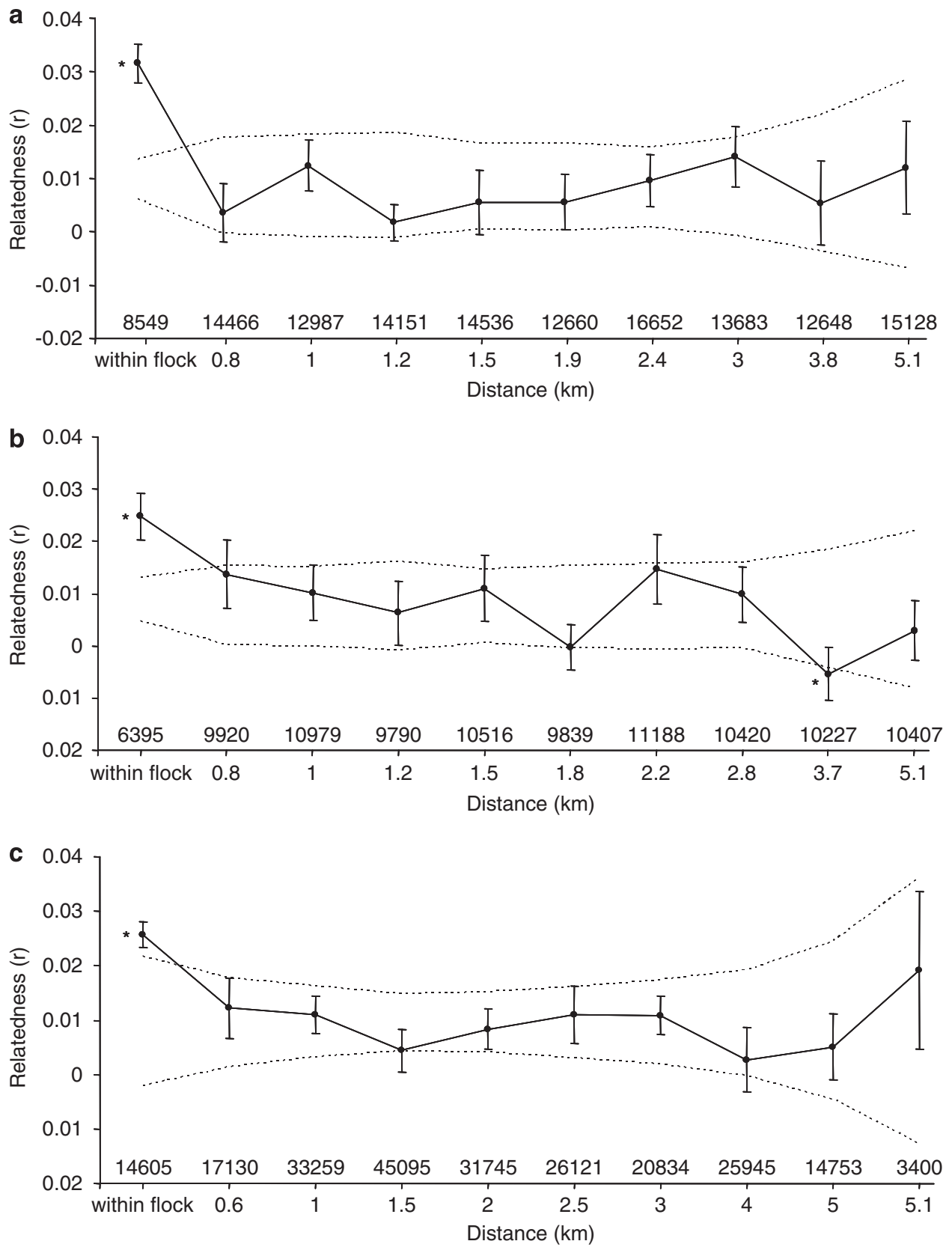

Figure 3 Average pairwise relatedness $(r)$ between individual vinous-throated parrotbills as a function of distance (in kilometres) among winter flocks: (a) relatedness among males only, (b) relatedness among females only, (c) relatedness between males and females. The first distance class include only individuals within a same winter flock. The null hypothesis of no spatial genetic structure is bounded by the $95 \%$ confidence intervals (dashed lines) generated by random permutations of individual genotypes over distance. Error bars for mean $r$ at each distance class were calculated by jackknifing over loci. Numbers above the $x$ axis represent the number of pairwise comparisons.

Table 4 Sexual difference in mean $F_{\mathrm{ST}}$, mean $(\mathrm{m} A I c)$ and variance (vAIc) of assignment index of vinous-throated parrotbills in the 17 winter flocks, estimated using the Biased Dispersal package in FSTAT 2.9.3.2

\begin{tabular}{lccc}
\hline & Male $(\mathrm{n}=521)$ & Female $(\mathrm{n}=448)$ & $\mathrm{P}$ \\
\hline $\mathrm{m}$ AIc & 0.2196 & -0.2553 & 0.045 \\
$\mathrm{v}$ AIc & 17.3705 & 19.1891 & 0.113 \\
$F_{\mathrm{ST}}$ & 0.0124 & 0.0087 & 0.050 \\
\hline
\end{tabular}

decisions of individuals should be sensitive to other factors such as density and sex ratio (Thomson et al., 1997; Kenward et al., 1999; Le Galliard et al., 2005;
Donald, 2007). Firstly, this study has shown that adult survival rate is low, but also extremely variable among years (Table 1). This variation may have dynamic effects on the social structure of the winter flock because the survival rate of adults may influence the rates of immigration and emigration, especially by juveniles (Arcese et al., 1992). For example, although there was a significant difference in adult survival rates between two winters (36 vs $17 \%$, Table 1), overall flock size did not differ between the two winters, indicating possible density-dependent recruitment or immigration. Determining these processes with observational data is 
2005

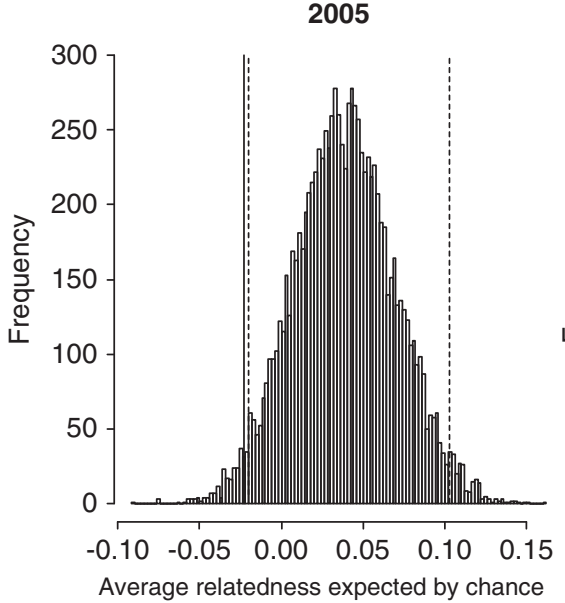

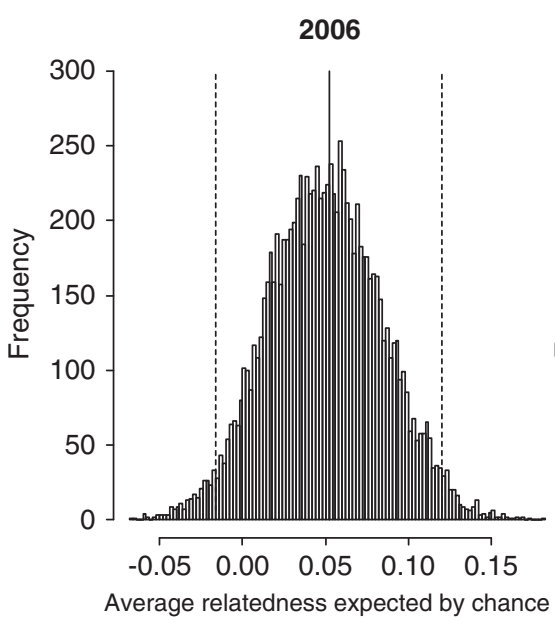

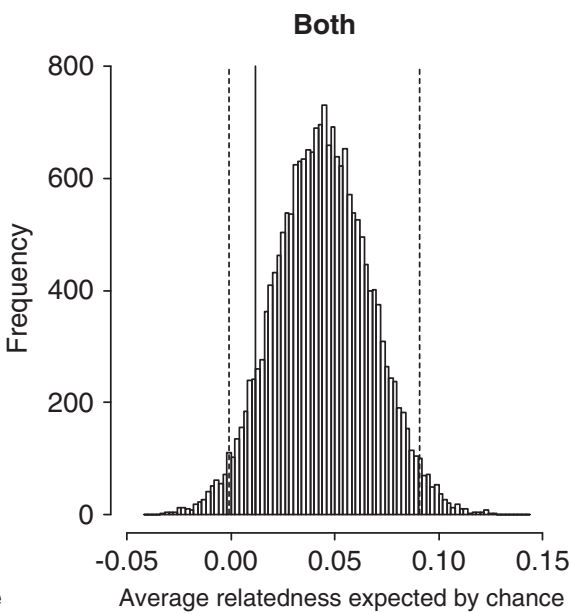

Figure 4 The histograms of the expected average relatedness between members of breeding pairs of vinous-throated parrotbills generated by random permutations (see the text for details) and location of observed average relatedness (thick lines) in 2005, 2006 and both combined, respectively. The null hypothesis of random mating is bounded by the $95 \%$ confidence intervals (dashed lines) and any observed values located outside the confidence intervals indicate the avoidance of inbreeding (if smaller than the lower CI) or outbreeding (if greater than the upper CI).

challenging, and a genetic approach offers a potential solution to understanding variation in animal dispersal strategies.

Secondly, in monogamous species like vinous-throated parrotbills, if the sex ratio of a winter flock where pairing occurs is skewed, members of one sex may lose breeding opportunities due to a lack of mates. In this study, we found that the sex ratio in each flock was not significantly skewed from 1:1, although there was a weak tendency of male bias. The observed sex ratio of winter flocks was consistent with the overall sex ratio of fledglings from the main study flocks, which was not significantly different from 1:1 (male/total: $0.54 ; n=153$; J.-W. Lee, unpublished data). In addition, there was no significant difference in the annual survival rate between adult males and females. On the whole, the balanced sex ratio in winter flocks may reduce individual movements and thus stabilize social structure of the winter flocks.

\section{Genetic differentiation}

Among 17 winter flocks, we found small (0.0004-0.025) but significant levels of genetic differentiation (Table 2) and the genetic structure among winter flocks was consistent with the model of isolation by distance (Wright, 1943). The range of $F_{\mathrm{ST}}(0.0004-0.025)$ is similar to that $(0-0.015)$ found at a much larger scale in whitebacked woodpecker Dendrocopos leucotos populations across northern Europe (Ellegren et al., 1999). However, the overall $F_{\mathrm{ST}}$ found in this study (0.01) was relatively small compared with $F_{\mathrm{ST}}$ from other avian studies conducted at a much larger geographic scale (more than several hundreds kilometres) which ranged from 0.04 to 0.1 (Grapputo et al., 1998; Martinez et al., 1999). Nevertheless, given that our study area was just $5 \mathrm{~km}$ long, the low level of genetic differentiation that we found implies that much greater genetic differentiation would be apparent at scales comparable to those studies.

The results of spatial autocorrelation analysis for relatedness indicated that both males and females within the same winter flock were more closely related to each other than those from different winter flocks. These results are highly consistent with the expectation from parrotbills' demographic and behavioural characteristics identified above, specifically adult flock fidelity, natal philopatry and dispersal of kin coalitions. Temporal genetic differentiation within a winter flock $(-0.002-$ 0.009 , Table 4) was much smaller than spatial genetic differentiation (0.001-0.02), again reflecting the behavioural features mentioned above. In addition, variations in the levels of temporal genetic differentiation indicate that the survival rate of adults also affected the genetic structure of winter flocks, structure being greatest when adult survival was lower (Tables 1 and 3). Taken together, the results of this study support the idea that genetic differentiation could be generated by behavioural and/ or demographic processes alone, without any physical barriers to dispersal, even at a fine spatial scale $(<5 \mathrm{~km}$ long in this study).

The extent of dispersal, gene flow and thus genetic differentiation among populations will influence the potential for local adaptation (Slatkin, 1985; Lenormand, 2002; Postma and van Noordwijk, 2005). Vinous-throated parrotbills are extreme habitat generalists, occupying habitats ranging from marshland, through lowlands, to mountain tops, and from rural to urban areas; they also show strong adaptability in nest site selection and nest building behaviour according to the habitat types (Jang, 1999). Limited gene flow induced by behavioural and demographic processes may be one factor that allows this species to inhabit various types of habitats through facilitation of local adaptation. It would be interesting to further examine the correlation between the levels of genetic differentiation between populations and the levels of habitat generality across species.

\section{Inbreeding}

Inbreeding depression has been demonstrated in many species and so inbreeding avoidance mechanisms would be expected when the risk of incest is high (Pusey and Wolf, 1996). Contrary to our expectation that the social 
and genetic circumstances of vinous-throated parrotbills would cause a high frequency of inbred mating, we found relatively low rates of inbreeding. However, the evidence for incest avoidance from our study is equivocal (Figure 4), with avoidance suggested in 1 year but not in the other. One of the principal mechanisms to avoid inbreeding is sex-biased natal dispersal (Greenwood and Harvey, 1982; Pusey and Wolf, 1996) but any sex bias we found was weak (Table 4; Figure 3; see also Lee et al., in review), suggesting that this may not be an effective mean of inbreeding avoidance in this species.

Another possible mechanism to avoid inbreeding is recognition of relatives (Blouin and Blouin, 1988; Pusey and Wolf, 1996) and empirical studies across many animal taxa support this possibility (Sharp et al., 2005; Facon et al., 2006; Gerlach and Lysiak, 2006; Archie et al., 2007; Lihoreau et al., 2007). Vinous-throated parrotbills may be able to discriminate relatives and non-relatives using some phenotypic characteristic, such as vocal cues, as in long-tailed tits Aegithalos caudatus (Sharp et al., 2005). However, the effectiveness of kin recognition as a mechanism of inbreeding avoidance is uncertain in this species because siblings from different broods might encounter each other and yet may not recognize each other as kin. In addition, frequent mate switching caused by high mortality will produce many half-siblings and this will generate kin structure with various levels of relatedness in flocks. Recognition of all relatives in such circumstances would require extremely sophisticated mechanisms. Nevertheless, we cannot rule out kin recognition as a mechanism of inbreeding avoidance in this species, so further study on this topic would be worthwhile.

Alternatively, the parrotbill's social system may reduce the chance of inbreeding. Pairing occurs within winter flocks (Kim et al., 1992; Kim, 1998), suggesting that each individual would have contact with many prospective mates, most of which are unrelated. This social environment may reduce the probability of inbreeding without specific mechanisms like kin recognition. Moreover, a relatively high mortality rate may also dilute the probability of mating with kin and it could also diminish the detrimental effect of inbreeding if inbreeding depression occurs only after several successive inbreeding events (dos Santos et al., 1995). Collectively, these social and demographic processes may decrease the chance of inbreeding and reduce selection against inbreeding without sex-biased dispersal and/or kin recognition.

In conclusion, our study shows that the large winter flocks of vinous-throated parrotbills are not random aggregations of individuals. Behavioural and demographic processes generate significant genetic differentiation among winter flocks at a fine spatial scale in the absence of physical barriers to dispersal. These findings suggest that populations may be kin-structured, even when there are no obvious family social structures. The occurrence of such 'cryptic' fine-scale genetic structure has potentially important implications for both beneficial (for example kin-selected cooperation) and costly (for example inbreeding) behaviours.

\section{Acknowledgements}

We thank Andrew MacColl and Stuart Sharp who kindly gave valuable comments on the paper, and Alain Frantz
Demography and genetic structure in parrotbills J-W Lee et al

and Shinichi Nakagawa for statistical advice. We are also grateful to Byoung-Soon Jang, Hee-Yoon Kim, Jeong-Chil Yoo, Myun-Sik Kim and Yun-Kyung Lee for their great help during fieldwork. Chun-Geun Kim provided a perfect accommodation for fieldwork and many residents in the study area kindly allowed us to observe birds on their land. We also thank Andy Krupa for invaluable tuition of genotyping techniques and Deborah Dawson and Gavin Hinten for providing unpublished primer sequences. Bird ringing and blood sampling were conducted under permits by Yangpyeong-gun and this work was partly funded by the University of Sheffield and the National Environment Research Council, UK (TB), for which we are most grateful.

\section{References}

Arcese P (1989). Intrasexual competition, mating system and natal dispersal in song sparrows. Anim Behav 38: 958-979.

Arcese P, Smith JNM, Hochachka WM, Rogers CM, Ludwig D (1992). Stability, regulation, and the determination of abundance in an insular song sparrow population. Ecology 73: 805-822.

Archie EA, Hollister-Smith JA, Poole JH, Lee PC, Moss CJ, Maldonado JE et al. (2007). Behavioural inbreeding avoidance in wild African elephants. Mol Ecol 16: 4138-4148.

Avise JC (1996). Three fundamental contributions of molecular genetics to avian ecology and evolution. Ibis 138: 16-25.

Baker AM, Mather PB, Hughes JM (2001). Evidence for longdistance dispersal in a sedentary passerine, Gymnorhina tibicen (Artamidae). Biol J Linn Soc 72: 333-343.

Blouin SF, Blouin M (1988). Inbreeding avoidance behaviors. Trends Ecol Evol 3: 230-233.

Cabe PR, Page RB, Hanlon TJ, Aldrich ME, Connors L, Marsh DM (2006). Fine-scale population differentiation and gene flow in a terrestrial salamander (Plethodon cinereus) living in continuous habitat. Heredity 98: 53-60.

Caizergues A, Ratti O, Helle P, Rotelli L, Ellison L, Rasplus J-Y (2003). Population genetic structure of male black grouse (Tetrao tetrix $\mathrm{L}$ in fragmented vs. continuous landscapes. Mol Ecol 12: 2297-2305.

Crawley MJ (2007). The $R$ Book. John Wiley \& Sons Ltd: Chichester.

Crochet PA (2000). Genetic structure of avian populationsallozymes revisited. Mol Ecol 9: 1463-1469.

Dobson FS (1998). Social structure and gene dynamics in mammals. J Mammal 79: 667-670.

Donald PF (2007). Adult sex ratios in wild bird populations. Ibis 149: 671-692.

dos Santos EM, Andreassen HP, Ims RA (1995). Differential inbreeding tolerance in two geographically distinct strains of root voles Microtus oeconomus. Ecography 18: 238-247.

Double MC, Peakall R, Beck NR, Cockburn A (2005). Dispersal, philopatry, and infidelity: dissecting local genetic structure in superb fairy-wrens (Malurus cyaneus). Evolution 59: 625-635.

Ellegren H, Carlson A, Stenberg I (1999). Genetic structure and variability of white-backed woodpecker (Dendrocopos Leucotos) populations in northern Europe. Hereditas 130: 291-299.

Facon B, Ravigne V, Goudet J (2006). Experimental evidence of inbreeding avoidance in the hermaphroditic snail Physa acuta. Evol Ecol 20: 395-406.

Fowler AC (2005). Fine-scale spatial structuring in cackling Canada geese related to reproductive performance and breeding philopatry. Anim Behav 69: 973-981.

Francisco MR, Gibbs HL, Galetti M, Lunardi VO, Junior PMG (2007). Genetic structure in a tropical lek-breeding bird, the blue manakin (Chiroxiphia caudata) in the Brazilian Atlantic Forest. Mol Ecol 16: 4908-4918. 
Gabor TM, Hellgren EC, Bussche RA, Silvy NJ (1999). Demography, sociospatial behaviour and genetics of feral pigs (Sus scrofa) in a semi-arid environment. J Zool 247: 311-322.

Gardner MG, Bull CM, Cooper SJB, Duffield GA (2001). Genetic evidence for a family structure in stable social aggregations of the Australian lizard Egernia stokesii. Mol Ecol 10: 175-183.

Garnier S, Alibert P, Audiot P, Prieur B, Rasplus JY (2004). Isolation by distance and sharp discontinuities in gene frequencies: implications for the phylogeography of an alpine insect species, Carabus solieri. Mol Ecol 13: 1883-1897.

Gerlach G, Lysiak N (2006). Kin recognition and inbreeding avoidance in zebrafish, Danio rerio, is based on phenotype matching. Anim Behav 71: 1371-1377.

Goudet J (1995). FSTAT (Version 1.2): a computer program to calculate F-statistics. I Hered 86: 485-486.

Goudet J (2001). FSTAT, a Program to Estimate and Test Gene Diversities and Fixation Indices (Version 2.9.3). Lausanne University: Lausanne, Switzerland.

Goudet J, Perrin N, Waser P (2002). Tests for sex-biased dispersal using bi-parentally inherited genetic markers. Mol Ecol 11: 1103-1114.

Grapputo A, Pilastro A, Marin G (1998). Genetic variation and bill size dimorphism in a passerine bird, the reed bunting Emberiza schoeniclus. Mol Ecol 7: 1173-1182.

Greenwood PJ, Harvey PH (1982). The natal and breeding dispersal of birds. Annu Rev Ecol Syst 13: 1-21.

Griffiths R, Double MC, Orr K, Dawson RJG (1998). A DNA test to sex most birds. Mol Ecol 7: 1071-1075.

Hamilton WD (1964). The genetic evolution of social behaviour I and II. J Theor Biol 7: 1-52.

Hamilton WD, May RM (1977). Dispersal in stable habitats. Nature 269: 578-581.

Hardy OJ, Vekemans X (2002). SPAGeDi: a versatile computer program to analyse spatial genetic structure at the individual or population levels. Mol Ecol Notes 2: 618-620.

Jang BS (1999). Breeding ecology of the vinous-throated parrotbill Paradoxornis webbianus. MSc thesis. Kyung Hee University.

Johnson ML, Gaines MS (1990). Evolution of dispersal: theoretical models and empirical tests using birds and mammals. Annu Rev Ecol Syst 21: 449-480.

Keller LF, Waller DM (2002). Inbreeding effects in wild populations. Trends Ecol Evol 17: 230-241.

Kenward RE, Marcstrom V, Karlbom M (1999). Demographic estimates from radio-tagging: models of age-specific survival and breeding in the goshawk. I Anim Ecol 68: 1020-1033.

Kim CH (1998). Social behaviour of the crow tit (Paradoxornis webbiana) during the breeding season. Korean J Ornithol 5: 17-26.

Kim CH, Yamagishi S, Won PO (1992). Social organization of the crow tit (Paradoxonis webbiana) during the non-breeding season. Jpn J Ornithol 40: 93-107.

Knutsen H, Jorde PE, Andre C, Stenseth NC (2003). Fine-scaled geographical population structuring in a highly mobile marine species: the Atlantic cod. Mol Ecol 12: 385-394.

Krause J, Ruxton GD (2002). Living in Group. Oxford University Press: New York.

Le Galliard J-F, Fitze PS, Ferriere R, Clobert J (2005). Sex ratio bias, male aggression, and population collapse in lizards. Proc Natl Acad Sci USA 102: 18231-18236.

Lee J-W, Jang B-S, Dawson DA, Burke T, Hatchwell BJ (2009). Fine-scale genetic structure and its consequence in breeding aggregation of a passerine bird. Mol Ecol 18: 2728-2739.

Lemmon D, Withiam ML, Barkan CPL (1997). Mate protection and winter pair-bonds in black-capped chickadees. Condor 99: 424-433.

Lenormand $T$ (2002). Gene flow and the limits to natural selection. Trends Ecol Evol 17: 183-189.

Lihoreau M, Zimmer C, Rivault C (2007). Kin recognition and incest avoidance in a group-living insect. Behav Ecol 18: 880-887.
Martinez JG, Soler JJ, Soler M, Møller AP, Burke T (1999). Comparative population structure and gene flow of a brood parasite, the great spotted cuckoo (Clamator glandarius), and its primary host, the magpie (Pica pica). Evolution 53: 269-278.

McEachern M, Eadie J, Van Vuren D, Ecology Graduate G (2007). Local genetic structure and relatedness in a solitary mammal, Neotoma fuscipes. Behav Ecol Sociobiol 61: 1459-1469.

Nicholls JA, Austin JJ, Moritz C, Goldizen AW (2006). Genetic population structure and call variations in a passerine bird, the satin bowerbird, Ptilonorhynchus violaceus. Evolution 60: 1279-1290.

Nicholls JA, Double MC, Rowell DM, Magrath RD (2000). The evolution of cooperative and pair breeding in thornbills Acanthiza (Pardalotidae). J Avian Biol 31: 165-176.

Piertney SB, Maccoll ADC, Bacon PJ, Dallas JF (1998). Local genetic structure in red grouse (Lagopus lagopus scoticus): evidence from microsatellite DNA markers. Mol Ecol 7: 1645-1654.

Postma E, van Noordwijk AJ (2005). Gene flow maintains a large genetic difference in clutch size at a small spatial scale. Nature 433: 65-68.

Pusey A, Wolf M (1996). Inbreeding avoidance in animals. Trends Ecol Evol 11: 201-206.

Queller DC, Goodnight KF (1989). Estimating relatedness using genetic markers. Evolution 43: 258-275.

R Development Core Team (2008). R: A Language and Environment for Statistical Computing. $\mathrm{R}$ foundation for statistical computing: Vienna, Austria.

Ross KG (2001). Molecular ecology of social behaviour: analyses of breeding systems and genetic structure. Mol Ecol 10: 265-284.

Rousset F (1997). Genetic differentiation and estimation of gene flow from F-statistics under isolation by distance. Genetics 145: 1219-1228.

Schweizer M, Excoffier L, Heckel G (2007). Fine-scale genetic structure and dispersal in the common vole (Microtus arvalis). Mol Ecol 16: 2463-2473.

Severinghaus LL (1987). Social behavior of the vinous-throated parrotbill during the non-breeding season. Bull Inst Zool, Academia Sinica 26: 231-244.

Sharp SP, McGowan A, Wood MJ, Hatchwell BJ (2005). Learned kin recognition cues in a social bird. Nature 434: 1127-1130.

Shorey L, Piertney S, Stone J, Hoglund J (2000). Fine-scale genetic structuring on Manacus manacus leks. Nature 408: 352-353.

Slatkin M (1985). Gene flow in natural populations. Annu Rev Ecol Syst 16: 393-430.

Storz JF (1999). Genetic consequences of mammalian social structure. I Mammal 80: 553-569.

Sugg DW, Chesser RK, Dobson FS, Hoogland JL (1996). Population genetics meets behavioral ecology. Trends Ecol Evol 11: 338-342.

Taylor PD (1992). Altruism in viscous populations: an inclusive fitness model. Evol Ecol 6: 352-356.

Telfer S, Dallas JF, Aars J, Piertney SB, Stewart WA, Lambin X (2003). Demographic and genetic structure of fossorial water voles (Arvicola terrestris) on Scottish islands. I Zool 259: 23-29.

Temple HJ, Hoffman JI, Amos W (2006). Dispersal, philopatry and intergroup relatedness: fine-scale genetic structure in the white-breasted thrasher, Ramphocinclus brachyurus. Mol Ecol 15: 3449-3458

Thomson DL, Baillie SR, Peach WJ (1997). The demography and age-specific annual survival of song thrushes during periods of population stability and decline. J Anim Ecol 66: 414-424.

van Treuren R, Bijlsma R, Tinbergen JM, Heg D, Van De Zande L (1999). Genetic analysis of the population structure of socially organized oystercatchers (Haematopus ostralegus) using microsatellites. Mol Ecol 8: 181-187.

Watts PC, Rouquette JR, Saccheri IJ, Kemp SJ, Thompson DJ (2004). Molecular and ecological evidence for small-scale isolation by distance in an endangered damselfly, Coenagrion mercuriale. Mol Ecol 13: 2931-2945. 
Weir BS, Cockerham CC (1984). Estimating F-statistics for the analysis of population structure. Evolution 38: 1358-1370.

West SA, Pen I, Griffin AS (2002). Cooperation and competition between relatives. Science 296: 72-75.
Woxvold IA, Adcock GJ, Mulder RA (2006). Fine-scale genetic structure and dispersal in cooperatively breeding apostlebirds. Mol Ecol 15: 3139-3146.

Wright S (1943). Isolation by distance. Genetics 28: 114-138.

Supplementary Information accompanies the paper on Heredity website (http://www.nature.com/hdy) 